\title{
Knowledge and Practices of Pregnant Women regarding Oral Health in a Tertiary Care Hospital in Nepal
}

\author{
Neha Gupta, ${ }^{1}$ Manisha Chhetry ${ }^{2}$ \\ 'Department of Dental surgery, Nobel Medical College and Teaching Hospital, Biratnagar, Nepal, ${ }^{2}$ Department of Obstetrics \\ and Gynecology, BP Koirala Institute of Health Sciences, Dharan, Nepal.
}

\section{ABSTRACT}

Introduction: Poor dental hygiene has been associated with various perinatal complications in studies done worldwide but few studies in Nepal have explored the knowledge of pregnant ladies regarding dental hygiene. The aim of the study was to know the knowledge and practices of pregnant women regarding oral health in a tertiary care center in Nepal.

Methods: A qualitative study was carried out in Nobel Medical College and Teaching Hospital from January 15, 2018 to June 15, 2018 after approval from the Institutional Review Committee of Nobel Medical College. Convenience sampling was done. Fifty pregnant women admitted in antenatal ward were interviewed regarding their knowledge of dental care in pregnancy, the common dental problems they faced and the treatment taken. A predesigned proforma was used and results were analyzed using SPSS version 17.

Results: Twenty two (44\%) patients reported dental problems during pregnancy. Bleeding gums was seen in 7 (14\%) and toothache in 7 (14\%) were commonly reported dental problems. Forty seven $(94 \%)$ patients acknowledged that routine dental care was needed for health, only $6(12 \%)$ were aware that poor dental health could affect baby weight. Oral health not seen as priority in $24(48 \%)$ was the main barrier to seeking dental care in pregnancy followed by costs of treatment in $18(36 \%)$ and safety concerns in pregnancy in $8(16 \%)$ cases.

Conclusions: Though dental problems were a common occurrence in pregnancy, utilization of services was low for the same. The participants reported significant barriers to obtaining dental care including lack of knowledge about the importance of maternal oral health and the treatment costs.

Keywords: antenatal care; oral health; perinatal; pregnancy.

\section{INTRODUCTION}

Oral hygiene and its adverse perinatal outcome is an often neglected issue especially in a developing country like Nepal. With growing body of evidence, maintaining oral health in pregnancy has been recognized as an important health concern worldwide and neglect has been proven to be associated with adverse pregnancy outcomes like low birth weight, premature pre-labor rupture of membrane and prematurity with all its complications. The safety of dental treatment during pregnancy and its impact on improved perinatal outcomes have been well established in recent years. ${ }^{1-3}$ However, pregnant women often don't seek dental advice and treatment during pregnancy. ${ }^{4}$ Therefore to address this issue, it is fundamental to know the knowledge and prevalent practices regarding oral

Correspondence: Dr. Neha Gupta, Department of Dental surgery, Nobel Medical College and Teaching Hospital, Biratnagar, Nepal. Email: drnehadds@gmail.com, Phone: +977-9810580817. 
hygiene among the pregnant ladies. ${ }^{5}$

The aim of the study is to know the knowledge of pregnant women about oral health, to know the common dental problems in pregnancy and to identify the barriers in seeking care for dental problems in pregnancy in a tertiary care hospital of Nepal.

\section{METHODS}

This is a qualitative study where a survey of pregnant women admitted in antenatal ward in Nobel Medical College and Teaching Hospital in Nepal was undertaken from January 15, 2018 to June 15, 2018. Ethical approval was obtained from the Institutional Review Committee of Nobel Medical College and written informed consent was obtained from all participants. All pregnant ladies who were admitted to the maternity ward due to various complications of pregnancy or for delivery irrespective of the period of gestation and those who were willing to be included in the study were enrolled. Patients who did not give consent or were unable to give interview were excluded.

Convenience sampling method was used. Data was collected from 50 pregnant women and the participants were interviewed as per the pre-designed proforma. All data collected were entered in Excel and analyzed using SPSS version 17 .

\section{RESULTS}

The most common oral health problem reported by participants were bleeding gums in $7(14 \%)$ followed by toothache in 7 (14\%) participants (Table 1 ).

\begin{tabular}{|lc|}
\hline Table 1. Dental problems reported by the patients. \\
Patient reported problems & $\mathbf{n}(\%)$ \\
None & $28(56)$ \\
Bleeding gum & $7(14)$ \\
Sensitivity & $4(8)$ \\
Toothache & $7(14)$ \\
Cavities & $3(6)$ \\
Loose tooth & $0(0)$ \\
Others & $1(2)$ \\
\hline
\end{tabular}

The main barriers to seeking dental care for these women were oral health not seen as a priority in 24 $(48 \%)$, dental costs in $18(36 \%)$ and safety concerns regarding dental treatment during pregnancy in $8(16 \%)$ participants (Figure 1).

Further, only $5(10 \%)$ of pregnant women had seen a dentist in between 6 to 12 months. In terms of oral hygiene habits only $18(36 \%)$ of women reported brushing twice daily which indicate inadequate knowledge about maternal and infant oral health, especially relating to good oral hygiene habits during the prenatal period (Table 2).

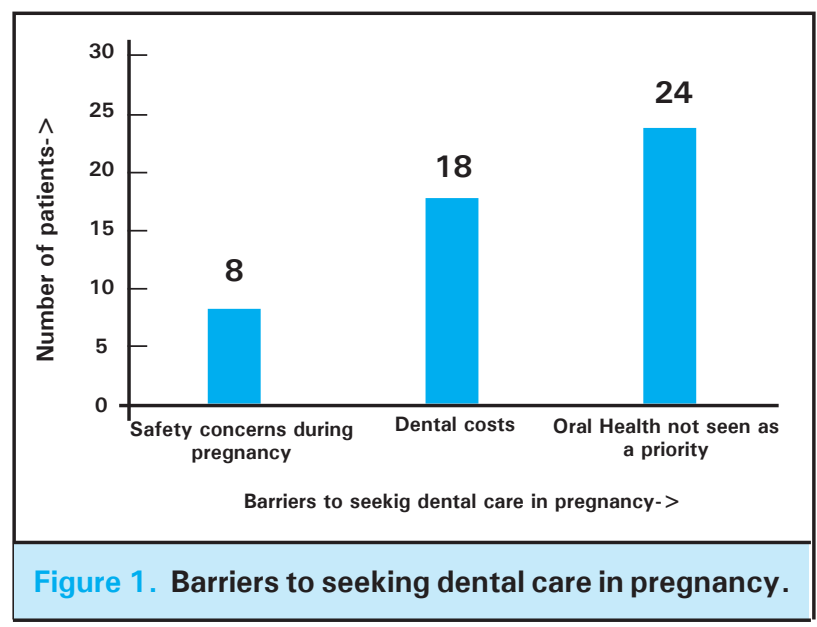

Table 2. Dental care of pregnant women.

Variables

n (\%)

How often do you brush?

$$
\text { once a day }
$$

Twice a day

Product used

Flouride toothpaste
Traditional products(eg.

Neem sticks" datwan")

When was the last time you saw a dentist?

$$
\begin{aligned}
& <6 \text { months } \\
& 6 \text { to }<12 \text { months } \\
& 1 \mathrm{yr} \text { to }<2 \mathrm{yrs} \\
& 2 \mathrm{yrs} \text { to }<5 \\
& >5 y \mathrm{rs}
\end{aligned}
$$

However, analysis of individual knowledge items showed that pregnant women had inadequate knowledge about potential impact of poor maternal oral health. Only 7 $(14 \%)$ women were aware that dental decay could spread from the mother to the baby's mouth and only 6 $(12 \%)$ women knew that mother's poor oral health may contribute to low birth weight baby. It is also apparent that some confusion exists among pregnant women regarding acquiring dental care both during pregnancy 
and early childhood. Nearly 42 (84\%) women were unsure about the best time for first dental visit for a baby (Table 3 ).

\begin{tabular}{|lc|}
\hline \multicolumn{2}{|l|}{ Table 3. Percentage of correct participant responses } \\
by individual survey items. & $\begin{array}{c}\text { Correct } \\
\text { response } \\
\text { Item content }\end{array}$ \\
$\begin{array}{l}\text { (\%) } \\
\text { Floss should be done daily to clean in } \\
\text { between teeth }\end{array}$ & $32 \%$ \\
$\begin{array}{l}\text { Routine dental visit help keep teeth and } \\
\text { gums healthy }\end{array}$ & $94 \%$ \\
$\begin{array}{l}\text { Dental decay can spread from the } \\
\text { motherto the babys mouth }\end{array}$ & $14 \%$ \\
A mothers poor oral health may \\
contribute to low birth weight baby \\
$\begin{array}{l}\text { The first tooth usually appears at around } \\
6 \text { months of age } \\
\text { Sleeping with bottle containing formula } \\
\text { could cause caries in baby }\end{array}$ & $70 \%$ \\
$\begin{array}{l}\text { First dental visit should be done between } \\
2-3 \text { yrs. }\end{array}$ & $12 \%$ \\
\hline
\end{tabular}

The age of expectant mothers were in the range of 17-38 years, with mean of $25.12 \pm 5.4$. Twenty eight $(56 \%)$ were primipara and $28(56 \%)$ of women had finished their primary education (Table 4). Forty five $(90 \%)$ women were in their third trimester.

\begin{tabular}{|ll|}
\hline \multicolumn{2}{|l|}{ Table 4. Socio demographic characteristics of } \\
patients. \\
Demographic variable & $\mathbf{n}(\%)$ \\
$<20 y r s$ & $6(12)$ \\
$20-30 y r s$ & $34(68)$ \\
$\geq 30 y r s$ & $10(20)$ \\
$<37$ wks & $1(2)$ \\
$37-40$ wks & $4(8)$ \\
$>40 w k s$ & $45(90)$ \\
Illiterate & $4(8)$ \\
Primary & $28(56)$ \\
Secondary and higher & $16(32)$ \\
Parity & \\
Primi & $28(56)$ \\
Multi & $22(44)$ \\
\hline
\end{tabular}

\section{DISCUSSION}

In this survey, pregnant mothers had poor knowledge regarding dental health during pregnancy. Mean age of the pregnant women in our study was of $25.12 \pm 5.4$ years and $56 \%$ of them were in their first pregnancy while in the study done by Yolanda Martinez- Beneytoa et $\mathrm{al}^{6}$ mean age was 30 years and $57.7 \%$ were expecting their first child. Similar results were observed by Adeniyi et al. ${ }^{7}$ This may be because of early marriage and early childbearing in our country and lower level of literacy. Ninety percent women surveyed revealed they did not attend the dentist during previous twelve months. These results were poorer as compared to study conducted in Sydney where $69.5 \%$ of pregnant women did not receive dental care during their most recent pregnancy. ${ }^{8}$ Similar studies done by Hullah et al showed that $33 \%$ of the English women visited the dentist during pregnancy..$^{9,10}$

In a study done in Jaipur, India by Mital et al the authors found that $42.5 \%$ of pregnant women brushed their teeth twice a day whereas in our study it was only $36 \% .{ }^{11}$ Similar studies done in Denmark showed a $96 \%$ of subjects brushed their teeth twice a day. ${ }^{12}$ In this study most of the pregnant women used flouride toothpaste (90\%) whereas 10\% used traditional products (eg. Neem sticks-datwan). Similar studies done in Sydney showed more than two thirdof pregnant women brush twice a day using flouridated toothpaste (98.3\%), mouthwash $(40.7 \%)$ and dental floss $(42.7 \%)$ or other oral hygiene products used. ${ }^{8}$ In our set up knowledge and use regarding dental products other than toothpaste was very poor. Only $10 \%$ of the subjects seeked dental consultation in last one year which is similar to study done in our neighbouring country India by Mittal et al ${ }^{11}$ $(11 \%)$ whereas utilization rates were higher $(45.6 \%)$ in study done by George et al. ${ }^{8}$

One of main reason for poor maternal oral health is the physiological changes in hormone levels and dietary changes during this period which predispose the pregnant women to various dental problems. ${ }^{10}$ This study showed that $44 \%$ of patients had reported dental problem which was comparable to studies done by George et $\mathrm{al}^{8}$ where it was around $46 \%$. But only $10 \%$ of these patients had visit to dentist in last one year even when a problem existed. The low use of dental services among pregnant women is well documented worldwide more so in underdeveloped and developing


in our study was mainly due to $(48 \%)$ oral health not seen as priority followed by high cost of dental services $(36 \%)$ and safety concern (16\%). Similar study done by George et al. showed cost of dental services as main barrier for seeking dentist (29.2\%). ${ }^{8}$ This highlights the basic lack of knowledge regarding the ill effects of dental problems on pregnancy. It is well documented that high dental cost are significant barrier for pregnant women seeking dental care worldwide..$^{2,16}$

The result from this study was almost same with study 
done in Sydney 8 about $97.9 \%$ of pregnant women agreed that routine dental visit help keep teeth and gums healthy. Only $12 \%$ of women acknowledged that poor oral health may contribute to low birth weight baby and first dental visit should be done between 2-3 yrs which was poorer as compared to other studies in developed countries. 7,8 In this study reported $72 \%$ of women showed knowledge that, sleeping with bottle containing formula could cause caries in babywhereas study done by George et $\mathrm{al}^{3}$ shown slightly higher rate (84\%) of women gave correct response. We can say that the dental knowledge and oral health practices are much better in developed countries when compared with that in Nepal. In this study most commonly reported dental problems during pregnancy were bleeding gums (14\%) and toothache $(14 \%)$, cavities $(6 \%)$ and sensitivity $(8 \%)$ which was similar to studies done elsewhere. ${ }^{7,8}$

The study has been done in small settings so the results cannot be generalized. It is recommended that further studies can be done in large settings.

\section{CONCLUSIONS}

This study highlights that poor maternal knowledge regarding oral health is significant issue in eastern Nepal because most of pregnant women do not visit dentist for their dental problems. There is a gap in knowledge and practices related to oral and dental healthcare in women during pregnancy. Oral health not seen as priority, followed by costs was the common barriers to seek dental care during pregnancy. The study suggest the need for preventive strategies involving dentists and antenatal providers to improve maternal oral health in eastern Nepal by reinforcing need to maintain good oral hygiene during pregnancy and the importance of dental visits. Larger studies are required to get a proper national scenario regarding this issue.

\section{ACKNOWLEDGEMENTS}

We would also like to thank Mr. Niraj Gupta, Dr. Bijay Sah for help in data entry and their feedback on study designs.

Conflict of interest: None.

\section{REFERENCES}

1. American Academy of Pediatric Dentistry. Guideline on Perinatal and infant oral health care [Internet]. Chicago: American Academy of Pediatric Dentistry; 2016. Available from: https://www.aapd.org/research/oral-healthpolicies--recommendations / perinatal-and-infant-oralhealth-care/. [Full Text]

2. California Dental Association. Oral Health During Pregnancy and Early Childhood [Internet]. Sacramento (US): California Dental Association Foundation. Available from: https:// www.cdafoundation.org/education/ perinatal-oral-health. [Full Text]

3. Michalowicz BS, DiAngelis AJ, Novak MJ, Buchanan W, Papapanou PN, Mitchell DA, et al. Examining the safety of dental treatment in pregnant women. J Am Dent Assoc. 2008;139:685-95. [PubMed]

4. George A, Johnson M, Blinkhorn A, Ellis S, Bhole S, Ajwani S. Promoting oral health during pregnancy: current evidence and implications for Australian midwives. J Clin Nurs. 2010;19(23-24):3324-33. [ [PubMed | Full Text]

5. American Academy of Pediatric Dentistry. Policy on Early Childhood Caries (ECC): Unique Challenges and Treatment Options. Chicago: American Academy of Pediatric Dentistry; 2011 [cited 2019 April 17]. Available from: https://www.aapd.org/research /oral-health- policies--recommendations/early-childhood-caries-uniquechallenges-and-treatment-options. [Full Text]

6. Martinez Beneytoa Y, Vera-Delgado MV, Perez L, Maurandi A. Self-reported oral health and hygiene habits, dental decay, and periodontal condition among pregnant European Women. Int J Gynecol Obstet. 2011;114(1):18-22. [라Med | Full Text]

7. Abiola A, Olayinka A, Mthida B, Ogunbiyi O. A survey of the oral Health Knowledge and practices of pregnant women in a Nigerian Teaching Hospital. Afr J Reprod Health. 2011 Dec;15(4):14-9. [PubMed]

8. George A, Johnson M, Blinkhorn A, Ajwani S, Bhole S, Yeo $\mathrm{AE}$, et al. The oral health status, practices and knowledge of pregnant women in south western Sydney. Aust Dent J. 2013 Mar;58(1):26-33. [Full Text]

9. Hullah E, Turok Y, Nauta M, Yoong W. Self reported oral hygiene Habits dental attendance and attitude to dentistry during pregnancy in a sample of immigrant women in North London. Arch Gynaecol Obstet. 2008;277(5):405-9. [PubMed [ Full Text]

10. Honkala S, At Ansari J. Self reported Oral health, oral hygiene habits and dental attendance of pregnant women in Kuwait. J Clin Periodontal. 2005;32(7):809-14. [PubMed | Full Text]

11. Mital P, Hooja N, Mital P, Salvi A, Fatima A. Oral and dental 
health knowledge, attitude and practice among pregnant women. Sch Acad J Biosci. 2014;2(9):627-32. [Full Text]

12. Christensen LB, Jeppe Jensen D, Peterson PE. Self reported gingival conditions and self care in the oral health of Danish women during pregnancy. J Clin Periodontol. 2003;30(11):949-53. [PubMed]

13. Gaffield ML, colley-Gilbert BJ, Malvitz DM, Romaguera R. Oral health during pregnancy. An analysis of information collected by the pregnancy Risk Assesment Monitoring System. J Am Dent Assoc. 2001;132:1009-16. [PubMed]

14. Dinas K, Achyropoulos V, Hatzipantells E, Mavromatidis G, Zepridis L, Theodoridis, et al. Pregnacy and oral health: utilization of dental services during pregnancy in northern Greece. Acta Obstet Gynecol Scand. 2007;86:938-44. [PubMed [ Full Text]

15. Saddki N, Yusoff A, Hwang YL. Factors associated with dental visit and barriers to utilization of oral health care services in a sample of antenatal mothers in Hospital Universiti Saina Malayia. BMC Public Health. 2010;10:75. [PubMed | Full Text]

16. Strafford K, Shellhaas C, Hade E. Provider and patient perceptions about dental care during pregnancy. J Matern Fetal Neonatal Med. 2008;21:63-71. [PubMed]

The Author(s) 2018.

This work is licensed under a Creative Commons Attribution 4.0 International License. The images or other third party material in this article are included in the article's Creative Commons license, unless indicated otherwise in the credit line; if the material is not included under the Creative Commons license, users will need to obtain permission from the license holder to reproduce the material. To view a copy of this license, visit http://creativecommons.org/licenses/by/4.0/ 